\title{
Illuminance required to detect a pavement obstacle of critical size
}

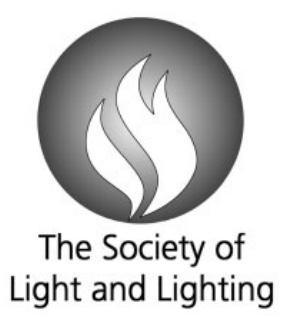

\author{
S Fotios PhD and J Uttley PhD \\ School of Architecture, University of Sheffield, Sheffield, UK
}

Received 20 May 2016; Revised 23 June 2016; Accepted 24 June 2016

\begin{abstract}
This paper investigates the illuminance needed to detect trip hazards for pedestrians walking after dark. In previous work, it was assumed that the critical obstacle height is $25 \mathrm{~mm}$ : further review of accident data and foot clearance data suggests instead that $10 \mathrm{~mm}$ is the critical height. Eye tracking records suggest a tendency for obstacles to be detected approximately $3.4 \mathrm{~m}$ ahead. Interpretation of obstacle detection data suggests horizontal photopic illuminances of up to 0.9 lux are required for peripheral detection of a $10 \mathrm{~mm}$ obstacle $3.4 \mathrm{~m}$ ahead, according to the scotopic/photopic ratio of the lighting and the age of the observer.
\end{abstract}

\section{Introduction}

This paper concerns pedestrians and their ability to detect obstacles that might otherwise lead to injury from a fall. An obstacle is defined here as a variation in elevation between adjacent surfaces on the footpath; such hazards are responsible for the majority of non-vehicular pedestrian accidents. ${ }^{1}$ This variation may be an increase in height (ascent) such as a raised paving slab or a decrease in height (descent) such as a pothole. A fall is likely to occur if this variation is unexpected and the subsequent misplacement of the foot causes the pedestrian to lose balance to an extent they are not able to recover. This misplacement may be the foot unexpectedly striking a surface or the absence of an expected surface.

Falls on public footpaths are a significant problem in terms of the number of cases, the severity of the resulting injury, and the national cost. ${ }^{1-4}$ A survey of postal delivery workers in the United Kingdom's Royal

Address for correspondence: Steve Fotios, School of Architecture, The University of Sheffield, The Arts Tower, Western Bank, Sheffield, S10 2TN, UK.

E-mail: steve.fotios@sheffield.ac.uk

(C) The Chartered Institution of Building Services Engineers 2015
Mail, a section of society regularly exposed to walking hazards, found that $86 \%$ listed damaged walking surfaces and large obstacles as a major factor in accident risk. ${ }^{2}$ In 2002, the annual number of falls on public footpaths requiring admission to the accident and emergency unit of a hospital in England and Wales was estimated to lie between 20,000 and $190,000 .^{3}$ The average economic cost (2007 data) of a tripping accident on a footway was estimated ${ }^{3}$ to be $£ 6,046$ and thus falls on public footpaths represent an annual cost to England and Wales of up to $£ 1.2$ billion. This is not a problem only within the United Kingdom. A survey in New Zealand found that around 700 pedestrians were admitted to hospital each year as a result of slips, trips and stumbles in the road environment. ${ }^{1}$ These data are recorded in New Zealand because their no-fault, stateowned injury compensation and rehabilitation provider keeps records of pedestrian injury claims. Of these, it was found that most injuries occurred on the roadside in residential areas, with vertical changes due to uneven construction being the most commonly reported hazard type in roadside pedestrian accidents. Footpath condition is 
a common concern that may prevent people from choosing to walk. ${ }^{5}$

While walking is the most common physical activity of older people it exposes the walker to increased risk of accident and falling. ${ }^{6}$ Reaction time decreases with age, and hence elderly people are less able to recover their balance in sufficient time after an accidental foot misplacement. Hospitalisation data from Australia (Figure 1) shows the elderly ( $>65$ years) are much more frequently injured due to a fall then younger people. ${ }^{7}$ A survey of claims made against three UK local authorities (1998-2002) found that more than half were associated with pedestrians aged over 60 years. ${ }^{3}$ When these data are weighted by distance walked, then it is clear that the elderly have a higher risk of falls than younger people. Compared with other non-self-inflicted causes of injury (i.e. fire, poisoning, drowning, road traffic) falls are by far the greatest cause of fatal injuries among older people $(60+$ years $)$ in the EU. ${ }^{8}$ Elderly falling is a major cause of disabilities in later life, and the reduced outdoor activity associated with a fall, or with fear of falling, reduces the benefits of health and social interaction. ${ }^{9}$ The elderly are apparently aware of this risk: a survey of residents in two Danish cities found that smooth pavement surfaces were particularly critical factors in route choice when walking for their elderly group ( $>70$ years old) while for the younger group (40-49 years old) a fast, direct route was more important. ${ }^{10}$ A study in Australia also revealed a perception that uneven footpaths are hazardous for the elderly and can prevent walking. ${ }^{11}$

A person is likely to trip and fall if they fail to notice an obstacle, if they have insufficient foot clearance, and if they fail to regain balance before falling. ${ }^{3}$ Road lighting may contribute to alleviating the first of these after dark by improving ability to detect and identify approaching obstacles in sufficient time to make changes to gait. Indeed, inadequate or poor lighting has been listed as a contributory factor in investigations of falls $\mathrm{s}^{2,4,12}$ and improving obstacle detection is one of the aims of road lighting on subsidiary roads such as those in residential areas. ${ }^{13,14}$

Early lighting guidance was provided by Caminada and van Bommel ${ }^{14}$ and they used data for emergency lighting as the basis of

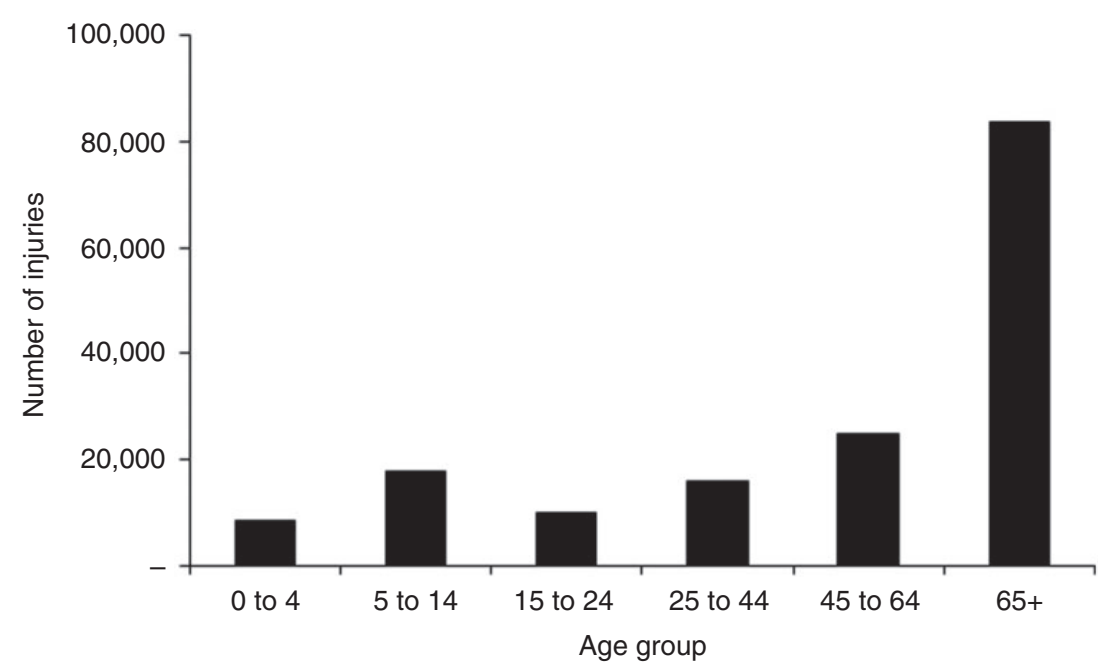

Figure 1 Injuries caused by tripping when walking on footpaths, Australia 2009-2010 according to age ${ }^{7}$ 
their recommendation for the detection of obstacles. They suggested illuminances in the range of 0.2 to 1.0 lux, these being taken from a draft CIE report. Confirmation is available from Boyce ${ }^{15}$ who comments also on the uncertainty of origin of the values. In an experiment investigating time and manner to walk an unfamiliar escape route it was found that at 0.2 lux there was difficulty in moving quickly and without hesitation, but at 1.0 lux there was no difficulty in moving smoothly and at a speed of movement similar to that under the normal room lighting (580 lux on the floor). ${ }^{15}$ Therefore 0.2 lux was presented as an absolute minimum, with 1.0 lux suggested to be more ideal.

Thies et al. ${ }^{16}$ examined gait characteristics (step width variability, step time and step time variability) when walking along flat and bumpy surfaces (prisms placed underneath a carpet) and they found no effect for the two light levels considered, 47lux and 927lux. These illuminances are higher than that likely to be encountered on pedestrian footpaths (e.g. the $\mathrm{CIE}^{17}$ recommends average illuminances in the range 2.0-15lux) and according to the results from Boyce ${ }^{15}$ these may already lie on the plateau of performance.

Studies have been carried out to investigate the effect of changes in lighting on the detection of peripheral obstacles. ${ }^{18-20}$ Two approaches were used to interpret these data. ${ }^{19}$ The first approach was to identify the transition between the escarpment and plateau regions of the performance versus illuminance graph: higher illuminances bring negligible improvement in performance but lower illuminances result in a rapid decline in performance. These results suggested a transition at approximately 2.0 lux. It was found that observer age and light source scotopic/ photopic (S/P) ratio affected detection only at the lowest illuminance used in those experiments $(0.2$ lux $) .{ }^{18,20}$ The second approach was to interpolate the illuminance needed to detect an obstacle of specific size. This size was suggested to be $25 \mathrm{~mm}$, with an expectation to detect this somewhere between two and ten paces ahead, and this resulted in an estimated optimum illuminance of 0.62 lux for young observers under HPS lighting. ${ }^{19}$ The support for this $25 \mathrm{~mm}$ height is somewhat limited however, and since target size affects detection, ${ }^{21}$ a better understanding of obstacle size enables a more robust analysis.

In order to improve ecological validity when estimating the light level needed for obstacle detection this article presents a further investigation of pavement obstacles, specifically the critical size as defined by the minimum height of an obstacle likely to lead to a fall and the typical distance ahead the pavement is scanned. These data are then used to refine the interpolation of the illuminance desirable for obstacle detection.

\section{Obstacle height}

\subsection{Pavement maintenance and liability}

The guide used previously ${ }^{19}$ as to the height of a pavement defect likely to cause a trip is the threshold used by a local authority for pavement maintenance. This is because the local authority has a statutory responsibility for maintenance of a pedestrian pavement so it may be found liable to claims for compensation arising from a fall causing injury unless they can demonstrate reasonable care to maintain the pavement. ${ }^{3,22,23}$ Within the United Kingdom, $25 \mathrm{~mm}$ (frequently stated as one inch) is a commonly used threshold amongst many local authorities. ${ }^{3,24}$ There is reference to a $25 \mathrm{~mm}$ threshold in an audit checklist to assess outdoor falls risk ${ }^{25}$ and in discussion of injuries arising from falls. ${ }^{26} \mathrm{It}$ is not, however, a universal standard; for example, one UK local authority states 'If a defect is more than $20 \mathrm{~mm}$ deep it will be considered hazardous and our inspector will mark it with yellow paint. Defects that are less than $20 \mathrm{~mm}$ deep wouldn't normally be considered a hazard. ${ }^{27}$ One possible reason for variation in the height 
threshold is maintenance response time, with footpaths having more frequent usage demanding a more rapid maintenance response and having a smaller size threshold. ${ }^{3}$

The basis for the $25 \mathrm{~mm}$ threshold is not stated in these sources: it may be partially derived from case law. A survey ${ }^{19}$ of the advice offered by solicitors to prospective clients found a recommendation that trip accidents associated with an obstacle of at least a certain size would be likely to lead to a successful case for compensation: this size was frequently $25 \mathrm{~mm}$, but heights of $15 \mathrm{~mm}$ and $20 \mathrm{~mm}$ were also found in some cases, again with no apparent justification in any case.

Height alone does not determine liability for a fall, ${ }^{22}$ consideration is also given to expectation $^{24,28,29}$ - in other words, the sensitivity of the observer to the stimulus in addition to its actual intensity. ${ }^{30}$ Cohen $^{28}$ discusses this from personal experience as an expert witness in US legal cases. In one case a pavement slab raised by $25-38 \mathrm{~mm}$ by tree roots was not proven to be liable for a trip because the raised slab was unobstructed, visible for an approach distance of at least $21 \mathrm{~m}$, and therefore should have been within the victim's normal line of sight. In a second case a pedestrian tripped on a depression of 'more than 1-1/2 inches' Despite the pavement being heavily cracked and in the victim's neighbourhood, and thus probably an expected hazard, the claim for compensation was successful because of alleged minimal lighting: 'the nearest street light was far behind her and caused her body to cast a growing shadow as she walked' and therefore she could not reasonably perceive the hazard.

One reason for raising doubt about using $25 \mathrm{~mm}$ as a critical value is that a threshold of $6 \mathrm{~mm}$ is used in New Zealand as the intervention standard for sudden changes in footpath level, ${ }^{31}$ and this was apparently derived from analysis of foot clearance. A more definitive record of obstacle height and trips is found in Bird. ${ }^{3}$ In 389 claims for injury compensation against three UK local authorities the obstacle height was recorded: the range of heights extended from less than $5 \mathrm{~mm}$ to $200 \mathrm{~mm}$, with a clear mode for obstacle heights in the range of $10-20 \mathrm{~mm}$ (Figure 2).

\subsection{Foot clearance}

Trips occur when the swing foot unexpectedly contacts an object or the ground ${ }^{32}$ and foot clearance therefore provides an indication as to whether an obstacle is likely to induce tripping. ${ }^{33,34}$ Minimum foot clearance (MFC) is the minimum vertical distance between the lowest part of the foot of the swing leg and the pavement surface during mid-swing in the gait cycle. ${ }^{35}$ If a pedestrian is walking along a pavement assumed to be flat and even but encounters a raised obstacle that was not seen or expected, then the obstacle may lead to a fall if the obstacle height is greater than their foot clearance.

Table 1 shows the MFC determined from video recordings of pedestrians walking along flat surfaces without obstacles. Reported average (mean or median) values of minimum clearance are in the range of $10-15 \mathrm{~mm}$. Using the average value to define a critical height means, however, that foot clearance was lower for approximately half of the steps. Table 1 therefore shows a lower measure of clearance defined by (according to the data given in original reports) either the lower quartile or the mean minus one standard deviation. These estimates are in the range of $7.8-12.8 \mathrm{~mm}$.

Table 1 does not suggest a consistent effect of age on median MFC. A systematic review ${ }^{35}$ of MFC studies also concluded this was not the case, with no effect of age on the average (mean or median) MFC; this conclusion was also reported by others ${ }^{36,32}$ for walking on flat surfaces and by Chen et al. ${ }^{39}$ for stepping over obstacles. What may lead to increased risk of tripping for the elderly is greater variability in $\mathrm{MFC}^{35}$ and when variability is 


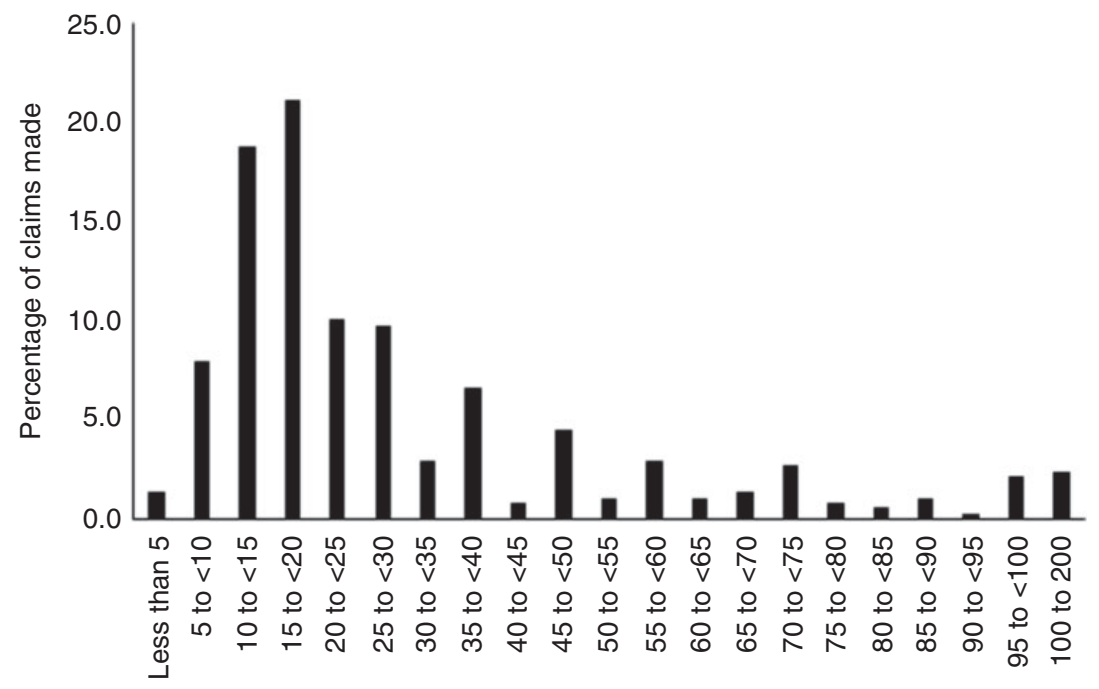

Obstacle height $(\mathrm{mm})$

Figure 2 Percentage of claims made against three local authorities in the United Kingdom (1998-2002) according to obstacle height, after Bird ${ }^{3}$

Table 1 Minimum foot clearance reported in past studies

\begin{tabular}{|c|c|c|c|c|}
\hline \multirow[b]{2}{*}{ Study } & \multirow[b]{2}{*}{ Method } & \multicolumn{2}{|c|}{ Minimum foot clearance (MFC) } & \multirow[b]{2}{*}{$\begin{array}{l}\text { Estimated critical } \\
\text { obstacle height }\end{array}$} \\
\hline & & Reported average & $\begin{array}{l}\text { Reported } \\
\text { measure of variance }\end{array}$ & \\
\hline Begg et al.. & $\begin{array}{l}17 \text { young females } \\
(26.4 \pm 4.9 \text { years }) \\
\text { walking on a treadmill } \\
16 \text { elderly females } \\
\text { (72.1 } \pm 4.4 \text { years) } \\
\text { walking on a treadmill }\end{array}$ & $12.9 \mathrm{~mm}(\text { median})^{\mathrm{b}}$ & $\mathrm{IQR}=9.6 \mathrm{~mm}$ & $9.4 \mathrm{~mm}^{\mathrm{c}}$ \\
\hline Best and Begg ${ }^{37 a}$ & $\begin{array}{l}\text { One male (aged } 32 \text { years) } \\
\text { walking on a treadmill }\end{array}$ & $10.3 \mathrm{~mm}$ (mean) & Std $\operatorname{dev}=2.5 \mathrm{~mm}$ & $7.8 \mathrm{~mm}^{\mathrm{d}}$ \\
\hline Mills et al. ${ }^{32 a}$ & $\begin{array}{l}10 \text { young males }(25.8 \pm 3.1 \text { years }) \\
\text { walking on a treadmill } \\
9 \text { old males }(71.1 \pm 3.4 \text { years }) \\
\text { walking on a treadmill }\end{array}$ & $\begin{array}{l}14.9 \mathrm{~mm} \text { (median) } \\
13.8 \mathrm{~mm} \text { (median) }\end{array}$ & $\begin{array}{l}\mathrm{IQR}=4.3 \mathrm{~mm} \\
\mathrm{IQR}=5.3 \mathrm{~mm}\end{array}$ & $\begin{array}{l}12.8 \mathrm{~mm}^{\mathrm{e}} \\
11.15 \mathrm{~mm}^{\mathrm{e}}\end{array}$ \\
\hline Winter ${ }^{38 a}$ & $\begin{array}{l}11 \text { adults, aged } 21-28 \text { years } \\
\text { walking on a level walkway }\end{array}$ & $12.9 \mathrm{~mm}$ (mean) & $\begin{array}{l}\text { Mean variability } \\
\quad=4.5 \mathrm{~mm}\end{array}$ & $8.4 \mathrm{~mm}^{\mathrm{f}}$ \\
\hline
\end{tabular}

${ }^{a}$ Report minimum toe clearance (MTC) rather than MFC.

${ }^{b}$ For Begg et al. ${ }^{36}$ these are the data reported in their Figure 3.

${ }^{\mathrm{c}}$ Reported lower quartile.

dMean minus standard deviation.

eMedian minus half the reported IQR.

'Mean minus reported 'variability.'

IQR: interquartile range.

Lighting Res. Technol. 2018; 50: 390-404 
accounted for in Table 1 (the estimated critical height) then the data from both Mills et al. and Begg et al. suggest a lower foot clearance for elderly people than younger people.

The data in Table 1 were obtained in situations where test participants were walking on a treadmill or other flat surface and not expecting a trip hazard. When a hazard is expected, foot clearance increases. ${ }^{39}$ This highlights a benefit of lighting in increasing the probability of detecting an otherwise unexpected hazard in sufficient time to enable gait change.

Best and Begg ${ }^{37}$ analysed the relationship between the height of an unseen (and therefore unexpected) obstacle and the probability of foot contact, modelling the number of strides before it is likely that a pedestrian would trip over an obstacle of a given height. For example, they suggest a $10 \mathrm{~mm}$ obstacle will be tripped over once every 2.1 strides, if unseen. Figure 3 shows this relationship, where the ordinate is the probability of tripping over an obstacle when encountered, calculated as $1 / n$ where $n$ is the number of strides before a trip. This trend closely resembles that reported by Frith and Thomas $^{1}$ (their Figure 2.5) for the proportion of people catching their foot on a defect plotted against the height of that defect.

According to Figure 3, an unseen obstacle of height $20 \mathrm{~mm}$ or more would almost certainly lead to foot contact and obstacles of height $12-15 \mathrm{~mm}$ are highly likely to lead to a trip $(p>80 \%)$ : it is therefore desirable for lighting to reveal such obstacles so that gait can be adjusted. Below this region the probability of foot contact begins to rapidly decrease. An unseen $10 \mathrm{~mm}$ obstacle has a $48 \%$ likelihood of causing a trip. There is little need for lighting to reveal anything smaller than approximately $8 \mathrm{~mm}$ because the probability of this leading to a trip is much reduced compared with larger obstacles.

\subsection{Obstacle height summary}

While a pavement defect of vertical height $25 \mathrm{~mm}$ is a commonly used threshold in the United Kingdom for prompting repair, there

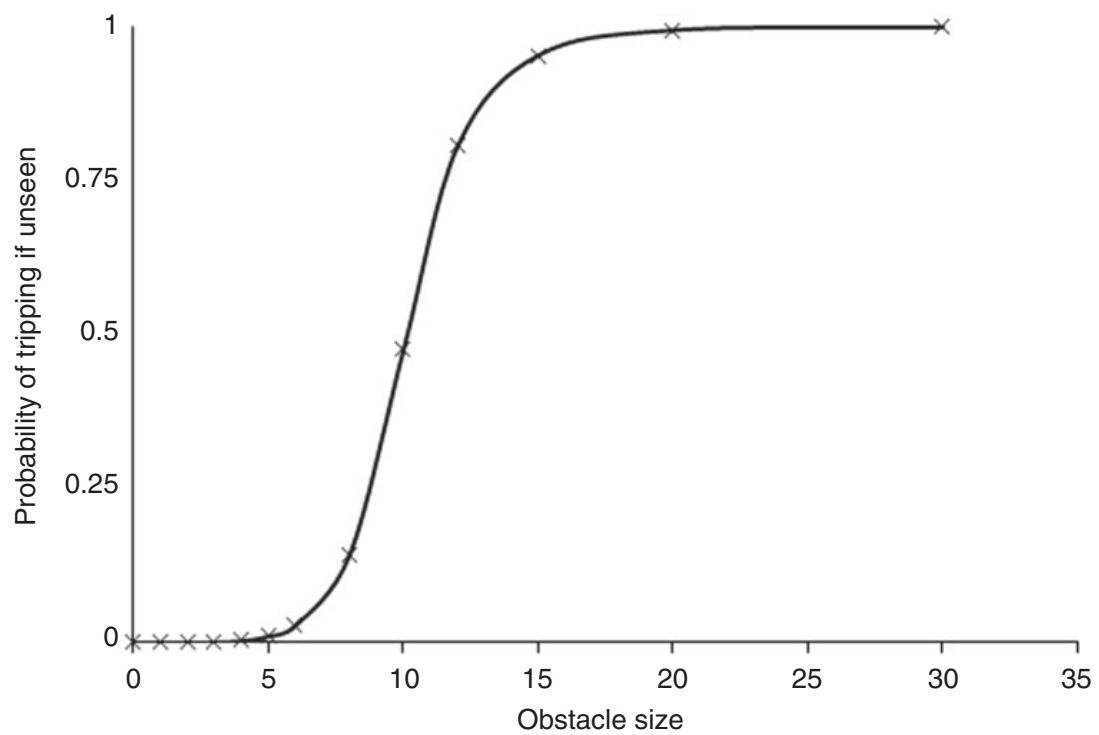

Figure 3 Probability of tripping over an unseen obstacle plotted against vertical height of that obstacle in millimetres ${ }^{37}$ 
is, however, no apparent empirical justification for this threshold other than the association made by those advising pedestrians to make claims against the local authority following a trip accident. We propose instead that the critical height is $10 \mathrm{~mm}$. This represents approximately the lower quartile of the range of minimum foot clearance measured when walking along a flat surface where hazards are not expected (Table 1) and the lower limit of the range of heights associated with the most frequent number of compensation claims (Figure 2). $10 \mathrm{~mm}$ is in the range $(8-15 \mathrm{~mm})$ where a change in height has a significant effect of the probability of falling over an unseen obstacle (Figure 3): below $8 \mathrm{~mm}$ the obstacle is unlikely to lead to a fall, but above $15 \mathrm{~mm}$ it is highly likely to lead to a fall.

\section{Detection distance}

Determining the size subtended by an obstacle at the observer's eyes requires an estimate of the distance ahead at which it was detected in addition to the change in vertical height. This detection distance was estimated by further analysis of previous work in which mobile eye tracking was used to investigate the gaze behaviour of 40 pedestrians walking outdoors along an urban route of approximately $900 \mathrm{~m}$, in daytime and after dark. ${ }^{4,41}$ The 40 pedestrians followed a nearidentical route, completing it in both forward and reverse directions on two separate occasions, resulting in the collection of eighty eye-tracking videos. The obstacles examined here are those which were fixated during critical times as marked using a concurrent auditory task, expected to provide significant cognitive capacity interference, ${ }^{42}$ and hence at these moments the participant's attention may have been focused specifically on what they were looking at.

For unpredictable environments, peripheral vision (particularly the lower peripheral field, as might be expected for coping with pavement hazards) is sufficient for successful avoidance of a suddenly appearing obstacle: foveal fixation plays a surprisingly minor role in visual guidance of locomotion and is generally not re-directed to either the obstacle or landing area. ${ }^{43,44}$ Graci et al. ${ }^{45}$ found that when the lower visual field was occluded, observers allowed significantly greater foot clearance and walked at a significantly slower speed - apparently safety strategies to offset the reduction in vision. Rietdyk and Rhea ${ }^{46}$ found that there was a higher probability of obstacle contact when the lower visual field was occluded for two steps before the obstacle compared with trials when full visual field was maintained. This is not to say that pedestrians do not look at an obstacle to plan avoidance, just that they do not always need to.

While obstacle detection is a peripheral visual task, eye tracking records foveal fixations. For this analysis it was assumed that peripheral detection occurred immediately preceding foveal fixation on an obstacle at critical moments, and hence the distance at which peripheral detection occurred was estimated as foveal fixation distance plus distance travelled between detection and fixation.

Foveal fixation distances were estimated from the eye tracking videos, as done in previous work. ${ }^{47}$ These judgements used as reference the approximate sizes of objects appearing in the field of view, such as vehicles, paving slabs and street benches that appeared in the videos. Two validation steps were used to counter potential errors in these estimates. ${ }^{48}$ First, a second coder made distance estimates for a sample $(22 \%)$ of the obstacles. These were reasonably consistent with the distance estimates of primary coder, with a Pearson's correlation coefficient of $0.72(p<0.01)$. Inter-rater reliability was assessed using a two-way mixed, consistency intra-class coefficient (ICC). The resulting ICC was in the 'Fair' range, ${ }^{49} \mathrm{ICC}=0.58$, 
suggesting there was reasonable agreement between the coders in terms of distance to the obstacle. The second validation step was to compare actual distances with estimated distances. Actual distances between observer and obstacle locations were measured in situ for 15 situations where the positions of observer and obstacle could be accurately established. These were compared with estimated distances for the same situations as recorded by the primary coder. It was found that estimated distances tended to be slightly shorter than actual distances, a mean ratio (estimated/actual) of 0.95 (std dev. 0.31). The mean distance of the 15 obstacle fixations for estimates and actuals was within $0.03 \mathrm{~m}$ (estimated mean $=4.80 \mathrm{~m}$, actual mean $=$ $4.83 \mathrm{~m}$ ). It was therefore concluded that the estimates of distance recorded by the primary coder were acceptably accurate.

To estimate travel distance between fixation and detection it was assumed that peripheral detection of the obstacle occurred during the immediately preceding fixation, i.e. $300 \mathrm{~ms}$ before the obstacle fixation, this being the average length of time for a fixation followed by a saccade. ${ }^{50}$ The distance travelled in this $300 \mathrm{~ms}$ period was estimated from the average walking speed of that participant, estimated from their personal eye tracking video.

There were 94 obstacle fixations at critical moments in 42 videos from 32 test participants, thus excluding those videos with poor eye-tracking signal or with no critical fixations towards obstacles. As shown in Figure 4 these detection distances tended to lie within $4 \mathrm{~m}$ of the observer. The distribution of distances was not found to be drawn from a normally distributed population. The median detection distance during critical times was $3.4 \mathrm{~m} \quad(\mathrm{IQR}=2.4-5.2 \mathrm{~m}, n=94$ obstacles).

This estimate compares well with that reported in previous work. Obstacle avoidance strategies include a change in gait (i.e. foot placement or foot clearance height), a change in navigation direction (steering) if the obstacle is too large to step over, or stopping. ${ }^{51,52}$ Gait change (adjusting step length and/or width) has a success rate of greater than $80 \%$ when a visual cue is available one step ahead. ${ }^{51}$ In contrast, steering has to be planned in the previous step cycle; success rate is near zero when only one-step cycle duration is available for changing direction. ${ }^{51,52}$ Patla and Vickers ${ }^{53}$ found that people fixated two steps ahead when instructed to step on specific targets (footprints) in the travel path. In summary, potential obstacles need to be seen approximately $3 \mathrm{~m}$ ahead to be negotiated without gait disturbance. ${ }^{54}$

An obstacle presenting a $10 \mathrm{~mm}$ change in vertical height that lies $3.4 \mathrm{~m}$ ahead subtends a visual angle of $8.47 \mathrm{~min}$ arc at the observer's eye for an assumed eye height of $1.5 \mathrm{~m}$. We refer to this as the critical size because smaller obstacles are unlikely to lead to a trip, and because larger obstacles should be at least as detectable as is this. The next section discusses the light level desirable to optimise detection of this obstacle.

\section{Lighting required to detect the critical obstacle}

Data regarding detection height and illuminance were taken from Uttley et al., ${ }^{20}$ this study being a development of previous work. ${ }^{18,19,55}$ Test participants were required to detect an obstacle in peripheral vision whilst walking and tracking a dynamic fixation target ahead of them, thus simulating some of the cognitive load of a pedestrian. In the pavement surface approximately $2.6 \mathrm{~m}$ in front of them, a cylindrical obstacle would begin rising upwards at intermittent times, and participants pressed a response button to indicate when they detected this obstacle. The height the obstacle had reached upon detection was recorded. This detection task was 


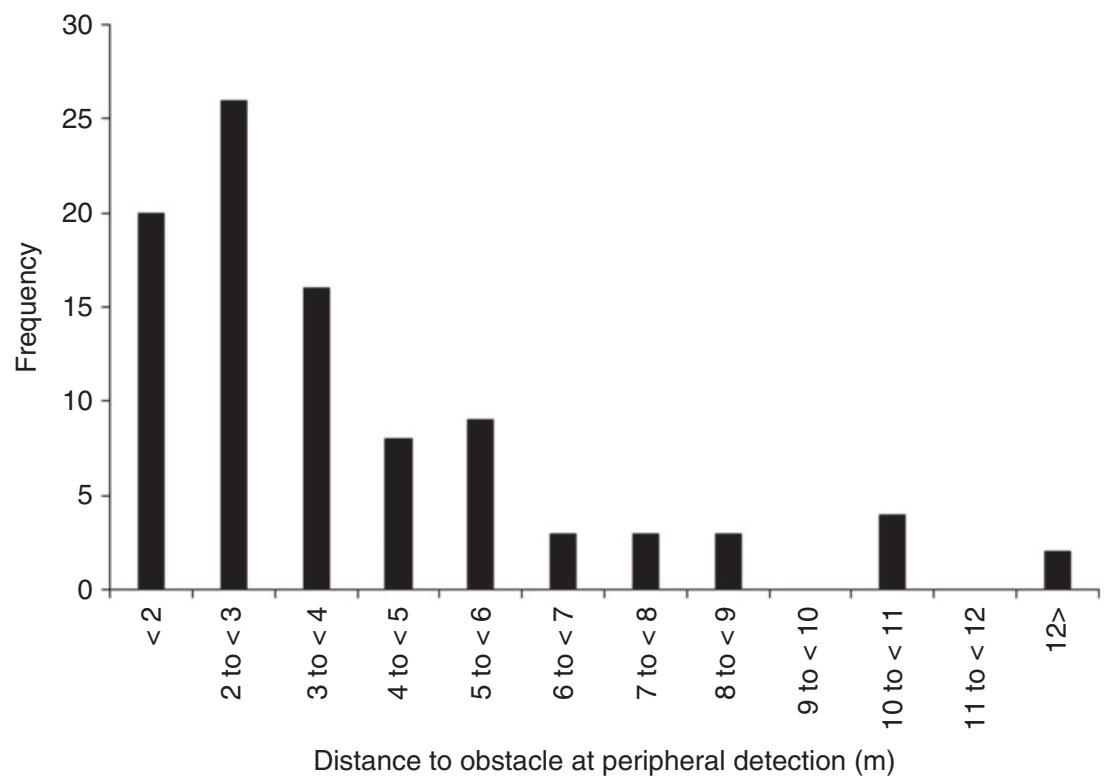

Figure 4 Distribution of distances to obstacles at peripheral detection $(n=94)$

carried out under five levels of photopic illuminance (0.2-20.0 lux, equating to a luminance range of $0.011-1.33 \mathrm{~cd} / \mathrm{m}^{2}$ ) and three scotopic/photopic (S/P) luminance ratios (1.2, 1.6 and 2.0$)$ by 30 test participants (15 younger, aged $<35$ years, and 15 older, aged $>50$ years). The mean detected heights of the obstacle under each light condition are shown in Figure 5.

To apply the results from this experiment to other detection distances, the vertical height $(\mathrm{mm})$ at which detection occurred was converted to visual angle (minutes of arc) subtended at the eye. Photopic illuminances were converted to mesopic luminances using the CIE system, ${ }^{56}$ which accounts for the influence of $\mathrm{S} / \mathrm{P}$ ratio on the results. Using these revised scales, lower quartile detected heights by mesopic luminance for young and old participants in Uttley et al. are plotted in Figure 6. Lower quartile values are used to ensure detection performance at the poorer end of the scale is reflected, thus ensuring results are inclusive of a range of performance levels, not just performance of the 'average' pedestrian. Data for the old and young test participants are considered separately and for each a line of best fit was plotted using a nonlinear least-squares regression model, produced by the $n l s$ package in $\mathrm{R} .{ }^{57}$ These models provide a good fit with the actual data, with a standard error of the regression values of $0.89 \mathrm{~min}$ arc for the young and 0.88 for the old model, and mean differences between predicted and actual values of $11 \%$ for the young model (std dev. $=9 \%$ ) and 9\% (std dev. $=7 \%$ ) for the old model.

For a target subtending $8.47 \mathrm{~min}$ arc at the observer's eye (the vertical size of a $10 \mathrm{~mm}$ obstacle at $3.4 \mathrm{~m}$ ) Figure 6 suggests mesopic luminances of 0.023 and $0.050 \mathrm{~cd} / \mathrm{m}^{2}$ for the younger and older observers respectively. Table 2 suggests a range of photopic illuminances from 0.22 lux up to 0.93 lux to detect this obstacle, depending on the $\mathrm{S} / \mathrm{P}$ ratio of the lamp and whether the observer is young or old. This conversion was carried out assuming a surface reflectance of $20 \%$, 


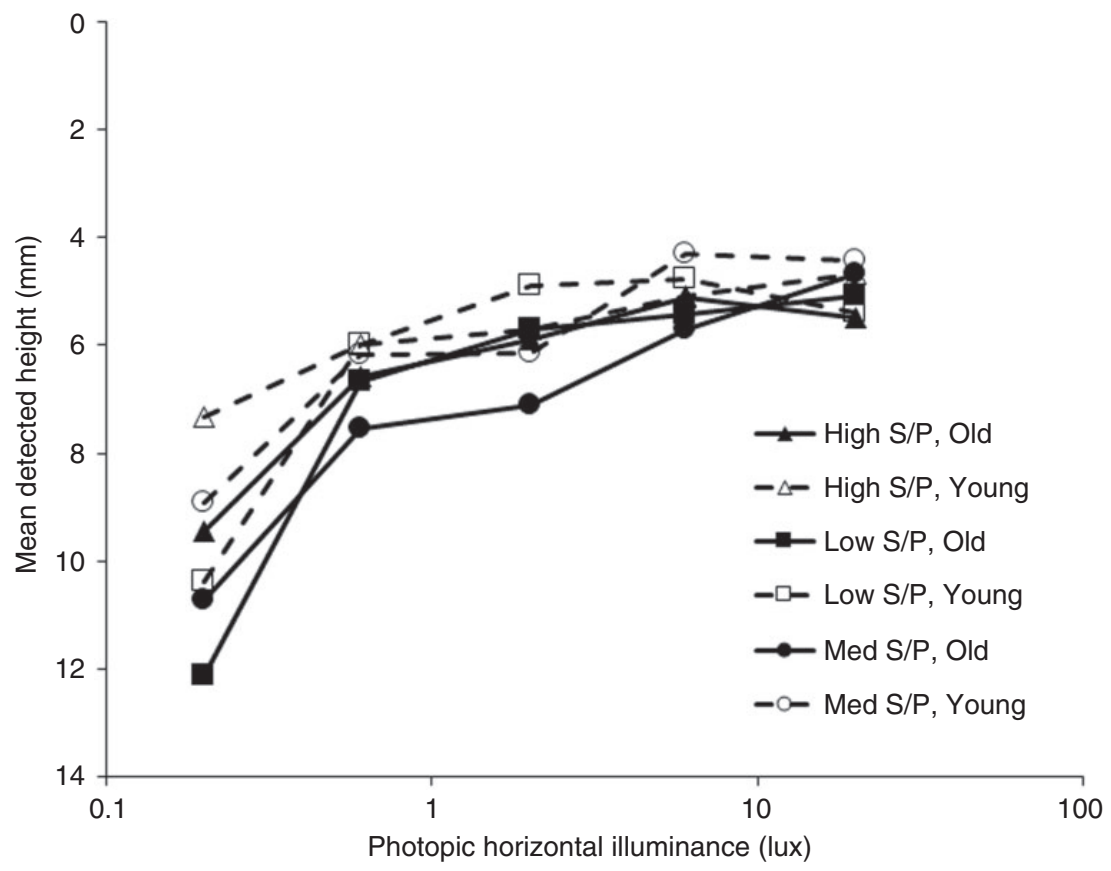

Figure 5 Mean height at which a rising obstacle was detected, this being located $2.6 \mathrm{~m}$ ahead at floor level, plotted against horizontal photopic illuminance, for different S/P levels and age groups ${ }^{20}$

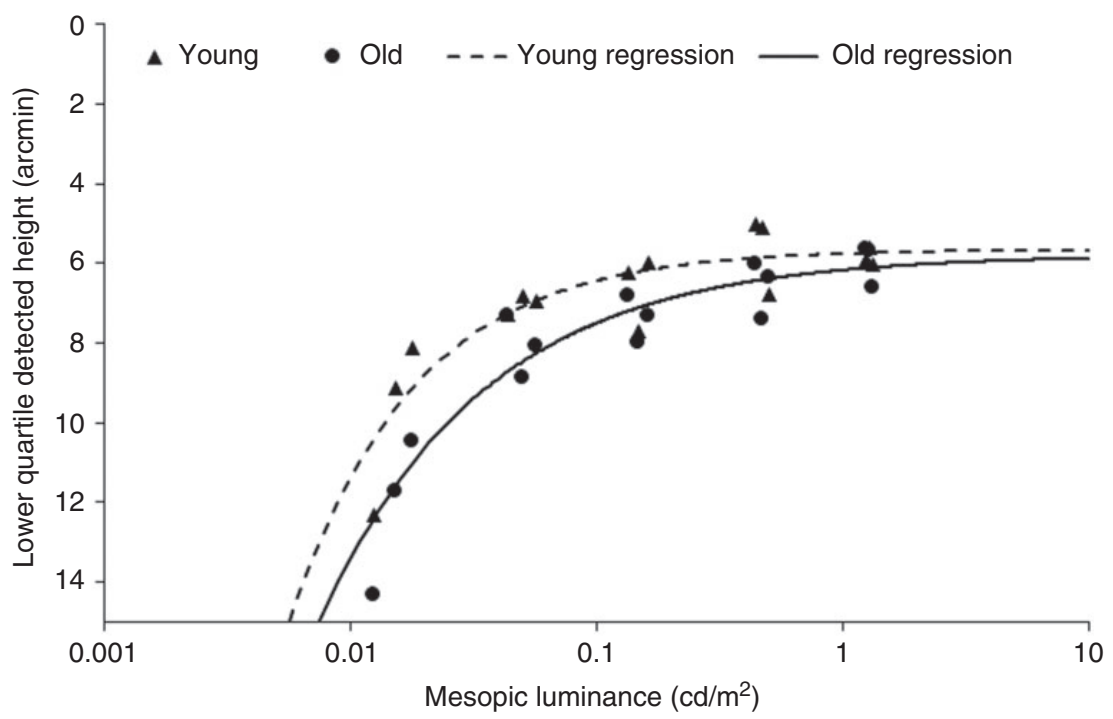

Figure 6 Lower quartile detected height in min arc plotted against mesopic luminance for young and old participants. Data from Uttley et al. ${ }^{20}$ 
Table 2 Photopic luminance and illuminance ranges required to detect $10 \mathrm{~mm}$ obstacle when located $3.4 \mathrm{~m}$ ahead for different road lighting lamp types and S/P ratios (indicative S/P ratios as given by the Lighting Industry Association ${ }^{58}$ )

\begin{tabular}{|c|c|c|c|c|c|}
\hline Lamp type & $\begin{array}{l}\text { Indicative } \\
\text { S/P ratio }\end{array}$ & $\begin{array}{l}\text { Age } \\
\text { group }^{a}\end{array}$ & $\begin{array}{l}\text { Mesopic } \\
\text { luminance } \\
\text { required }\end{array}$ & $\begin{array}{l}\text { Equivalent } \\
\text { photopic } \\
\text { luminance }\end{array}$ & $\begin{array}{l}\text { Equivalent } \\
\text { photopic } \\
\text { illuminance (lux })^{\mathrm{b}}\end{array}$ \\
\hline \multirow[t]{2}{*}{ High pressure sodium } & \multirow[t]{2}{*}{0.65} & Young & 0.023 & 0.029 & 0.46 \\
\hline & & Old & 0.050 & 0.059 & 0.93 \\
\hline \multirow[t]{2}{*}{ Metal halide } & \multirow[t]{2}{*}{1.20} & Young & 0.023 & 0.021 & 0.33 \\
\hline & & Old & 0.050 & 0.046 & 0.72 \\
\hline \multirow[t]{2}{*}{ LED } & \multirow[t]{2}{*}{2.18} & Young & 0.023 & 0.014 & 0.22 \\
\hline & & Old & 0.050 & 0.033 & 0.52 \\
\hline
\end{tabular}

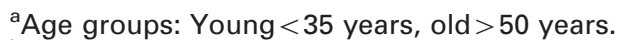

bPhotopic illuminance estimated assuming a surface reflectance of $20 \%$, which is typical for pavement surfaces.

which approximates that of an asphalt road having a luminance coefficient $\left(q_{0}\right)$ of 0.07 , which is that for the representative British road surface. ${ }^{13}$

\section{Conclusion}

It is proposed that $10 \mathrm{~mm}$ is the critical height of obstacle desirable for pedestrians to detect in order to reduce trips. This represents approximately the lower quartile of the range of minimum foot clearance measured when walking along a flat surface where hazards are not expected (Table 1) and the lower limit of the range of heights associated with the most frequent number of compensation claims (Figure 2). $10 \mathrm{~mm}$ is in the range $(8-15 \mathrm{~mm})$ where a change in height has a significant effect on the probability of falling over an unseen obstacle (Figure 3): below $8 \mathrm{~mm}$ the obstacle is unlikely to lead to a fall, but above $15 \mathrm{~mm}$ it is highly likely to lead to a fall. Eye tracking data suggests a tendency to detect obstacles located $3.4 \mathrm{~m}$ ahead, at which point the $10 \mathrm{~mm}$ obstacle subtends a visual angle of $8.47 \mathrm{~min}$ arc at the observer's eye.

Interpretation of the results of obstacle detection experiments ${ }^{20}$ suggests that horizontal illuminances in the range from 0.22 lux up to 0.93 lux are required to detect a $10 \mathrm{~mm}$ obstacle at $3.4 \mathrm{~m}$ distance, depending on the
$\mathrm{S} / \mathrm{P}$ ratio of the lamp and the age of the observer. These data ${ }^{20}$ show that higher illuminances lead to increased detection probability, and that the effect reaches a ceiling in the region of 2.0lux. It was found that observer age and light source $\mathrm{S} / \mathrm{P}$ ratio affected detection only at the lowest illuminance used in that experiment (0.2lux). Consideration of these results alongside those of Boyce ${ }^{15}$ suggests that a minimum photopic illuminance of 1.0 lux is sufficient light for pedestrians of all ages to safely detect and avoid trip hazards under any type of lamp.

While this illuminance is at the lower end of current recommendations for lighting in subsidiary roads, ${ }^{17}$ suggesting a lower design illuminance could be adopted in some situations, there is also a need to consider the effect of glare and the lighting required for other visual needs of pedestrians such as reassurance $^{59}$ and interpersonal judgements ${ }^{60}$ which may suggest different characteristics for road lighting.

This paper has tended to focus on ablebodied pedestrians: wheelchair users may have different demands. In addition to the need to negotiate obstacles, rough surfaces may also lead to muscular strain for manually propelled wheelchairs and to discomfort through whole-body vibrations. ${ }^{61,62}$ One US 
study investigated safe routes for disabled people but did not describe the nature of potential hazards. ${ }^{63}$ US guidance suggests a maximum obstacle height of $12.5 \mathrm{~mm}(0.5$ inches), this referring to a purposeful item such as a kerb rather than a defective surface. ${ }^{62}$ Further data are desirable.

This paper has focussed on the illuminance that might be optimum for pedestrians to detect pavement obstacles, horizontal illuminance being the main parameter of lighting that is defined in guidance for subsidiary roads, ${ }^{13,17}$ similar to discussion of obstacle detection using vehicle forward lighting. ${ }^{64}$ Whilst, for a specific obstacle, a change in illuminance can change the ability to detect that obstacle, ${ }^{18-20}$ detection is also affected by the contrast of the obstacle against its surroundings. For a peripheral target, detection improves with targets of increasing luminance contrast, although there is an interaction between contrast, illuminance and light source spectral power distribution. ${ }^{65}$

The empirical data employed above to determine an optimum illuminance were derived from an experiment ${ }^{20}$ using a single obstacle. This obstacle had sides and surroundings of identical reflectance, simulating a raised paving slab, and presented a luminance contrast of -0.7 (as derived using $\mathrm{C}=\left(L_{t}-L_{b}\right) / L_{b}$, with $L_{t}$ being the luminance of the raised side of the obstacle and $L_{b}$ being the luminance of surrounding horizontal surfaces). This high contrast arises because the obstacle was lit by LED arrays positioned almost directly above the obstacle, with no additional light sources, thus resulting in relatively high horizontal illuminance and low vertical illuminance. The experiment ${ }^{20}$ was designed to investigate changes in illuminance and spectral power distribution and contrast was therefore held constant. Many factors affect obstacle contrast, including the nature of the surfaces of the raised and surrounding materials and the spatial distribution of road lighting, this being determined by parameters including lantern optics and the height and spacing of lamp posts. For example, increased distance between poles reduces visibility of a target. ${ }^{66}$ It is therefore expected that pavement obstacles present a range of contrasts, for which the empirical data used here ${ }^{20}$ represent only one, and an extension of the relative visual performance model ${ }^{67}$ might be a useful tool for exploring the implications.

It must also be remembered that lighting alone is not the only approach to reducing the frequency of pedestrian trips. For example, pavement irregularity caused by the movement of paving slabs could be alleviated by making paving slabs with a chamfered edge.

\section{Acknowledgement}

Eye tracking validation was carried out with assistance from Hussain Qasem and Scott Fox, both of the University of Sheffield.

\section{Declaration of conflicting interests}

The authors declared no potential conflicts of interest with respect to the research, authorship, and/or publication of this article.

\section{Funding}

The authors disclosed receipt of the following financial support for the research, authorship, and/or publication of this article: This work was carried out with support from the Engineering and Physical Sciences Research Council (EPSRC) (grant number EP/ M02900X/1).

\section{References}

1 Frith W, Thomas J. The Mechanisms and Types of Non-motor Vehicle Injuries to Pedestrians in the Transport System and Indicated Infrastructure Implications. NZ Transport

Lighting Res. Technol. 2018; 50: 390-404 
Agency Research Report 431. Wellington: NZ Transport Agency, 2010.

2 Bentley TA, Haslam RA. Identification of risk factors and countermeasures for slip, trip and fall accidents during the delivery of mail. Applied Ergonomics 2001; 32: 127-134.

3 Bird S. The risk of tripping accidents on public footways. Municipal Engineer 2008; 161: 129-136.

4 Haslam RA, Bentley TA. Follow-up investigations of slip, trip and fall accidents among postal delivery workers. Safety Science 1999; 32: 33-47.

5 Ariffin RNR, Zahari RK. Perceptions of walking environments. Procedia-Social and Behavioural Sciences 2013; 105: 589-597.

6 Tournier I, Dommes A, Cavallo V. Review of safety and mobility issues among older pedestrians. Accident Analysis and Prevention 2016; 91: 24-35.

7 Tovell A, McKenna K, Bradley C, Pointer S. Hospital Separations Due to Injury and

Poisoning, Australia 2009-10. Injury Research and Statistics Series 69. Cat. No. INJCAT 145. Canberra: Australian Institute of Health and Welfare, 2012.

8 Feypell V, Methorst R, Hughes T. Non-motor Pedestrian Accidents: A Hidden Issue. OECD International Transport Forum: Pedestrian Safety, Urban Space and Health. Paris: OECD, 2012.

9 Sugiyama T, Ward Thompson C. Outdoor environments, activity and the well-being of older people: Conceptualising environmental support. Environment and Planning A 2007; 39: 1943-1960.

10 Bernhoft IM, Carstensen G. Preferences and behaviour of pedestrians and cyclists by age and gender. Transportation Research Part F 2008; 11: 83-95.

11 van Kamp I, Santos J, Du W, Olivier J, Hatfield J. Outdoor hazards and falls among community-dwelling older Australians. Healthy Aging Research 2014; 3: 17.

12 Fothergill J, O'Driscoll D, Hashemi K. The role of environmental factors in causing injury through falls in public places. Ergonomics 1995; 38: 220-223.

13 British Standards Institution. BS 5489-1:2013. Code of Practice for the Design of Road
Lighting: Lighting of Roads and Public Amenity Areas. London: BSI, 2012.

14 Caminada JF, van Bommel WJM. New lighting criteria for residential areas. Journal of the Illuminating Engineering Society 1984; 13: 350-358.

15 Boyce PR. Movement under emergency lighting: The effect of illuminance. Lighting Research and Technology 1985; 17: 51-71.

16 Thies SB, Richardson JK, Ashton-Miller JA. Effects of surface irregularity and lighting on step variability during gait: A study in healthy young and older women. Gait and Posture 2005; 22: 26-31.

17 Commission Internationale de l'Éclairage. Lighting of Roads for Motor and Pedestrian Traffic. CIE 115:2010. Vienna: CIE, 2010.

18 Fotios SA, Cheal C. Obstacle detection: A pilot study investigating the effects of lamp type, illuminance and age. Lighting Research \& Technology 2009; 41: 321-342.

19 Fotios S, Cheal C. Using obstacle detection to identify appropriate illuminances for lighting in residential roads. Lighting Research and Technology 2013; 45: 362-376.

20 Uttley J, Fotios S, Cheal C. Effect of illuminance and spectrum on peripheral obstacle detection by pedestrians. Lighting Research and Technology 2015. DOI: 1477153515602954.

21 Boyce PR. Human Factors in Lighting. 3rd Edition, Boca Raton, FL: CRC Press, 2014.

22 Butcher L. Standard Note SN/BT/627. Roads: Pedestrian Accidents on the Pavement. London: House of Commons Library, 2010.

23 Wahid RL. Who pays when a pedestrian trips and falls on a defective city sidewalk? An overview of Arizona case law. Arizona State Law Journal 1989; 21: 1163-1180.

24 UK Highways Liability Joint Task Group. Highway Risk and Liability Claims: A Practical Guide to Appendix $C$ of the Roads Board Report "Well Maintained Highways Code of Practice for Highway Maintenance Management". 2005

25 Curl A, Ward Thompson C, Aspinall P, Ormerod M. Developing an audit checklist to assess outdoor falls risk. ICE Urban Design and Planning. Retrieved 24 February 2016, 
from https://www.researchgate.net/profile/ Angela_Curl2/publication/280066010_Develo ping_an_audit_checklist_to_assess_outdoor_ falls_risk/links/55a6331 $\bar{d} 08$ ae5e82ab1fe21f.pdf

26 David HG, Freedman LS. Injuries caused by tripping over paving stones: An unappreciated problem. BMJ 1990; 300: 784-785.

27 Sheffield City Council. Maintenance of roads and footpaths (highways). Retrieved 21

December 2011, from https://www.sheffield. gov.uk/roads/maintenance/maintenance.html.

28 Cohen HH. Why do we bump into things while walking? - revisited. Ergonomics in Design:

The Quarterly of Human Factors Applications 2003; 11: 12-15.

29 Kwasniak A, Cuadrado J, Kuzel M, Sinocruz J. Evaluating public awareness of trip hazards on outdoor walkways: Proceedings of the Human Factors and Ergonomics Society 56th Annual Meeting, 2012, pp. 639-642.

30 Shang H, Bishop ID. Visual thresholds for detection, recognition and visual impact in landscape settings. Journal of Environmental Psychology 2000; 20: 125-140.

31 NZ Transport Agency. Pedestrian Planning and Design Guide. Wellington: NZ Transport Agency, 2009.

32 Mills PM, Barrett RS, Morrison S. Toe clearance variability during walking in young and elderly men. Gait and Posture 2008; 28: 101-107.

33 Haslam RA. Slip, trip and fall accidents. In: Karwowski W. (ed). International Encyclopedia of Ergonomics and Human Factors. Vol. III, New York: Taylor and Francis, 2001, pp. 1591-1593.

34 Marletta W. Trip, slip, and fall prevention. In: Hansen DJ. (ed). The Working Environment. Volume 1. Occupational Health Fundamentals. Chelsea, MI: Lewis Publishers, 1991, pp. 241-276.

35 Barrett RS, Mills PM, Begg RK. A systematic review of the effect of ageing and falls history on minimum foot clearance characteristics during walking. Gait and Posture 2010; 32: 429-435.

36 Begg R, Best R, Dell'Oro L, Taylor S. Minimum foot clearance during walking: Strategies for the minimization of trip-related falls. Gait and Posture 2007; 25: 191-198.
37 Best R, Begg R. A method for calculating the probability of tripping while walking. Journal of Biomechanics 2008; 41: 1147-1151.

38 Winter DA. Foot trajectory in human gait: A precise and multifactorial motor control task. Physical Therapy 1992; 72: 45-53.

39 Chen H-C, Ashton-Miller JA, Alexander NB, Schultz AB. Stepping over obstacles: Gait patterns of healthy young and old adults. Journal of Gerontology: Medical Sciences 1991; 46: M196-M203.

40 Fotios S, Uttley J, Cheal C, Hara N. Using eye-tracking to identify pedestrians' critical visual tasks, Part 1. Dual task approach. Lighting Research and Technology 2015; 47: 133-148.

41 Fotios S, Uttley J, Yang B. Using eye-tracking to identify pedestrians' critical visual tasks. Part 2. Fixation on pedestrians. Lighting Research and Technology 2015; 47: 149-160.

42 Weerdesteyn V, Schillings AM, van Galen GP, Duysens J. Distraction affects the performance of obstacle avoidance during walking. Journal of Motor Behavior 2003; 35: 53-63.

43 Franchak JM, Adolph KE. Visually guided navigation: Head-mounted eye-tracking of natural locomotion in children and adults. Vision Research 2010; 50: 2766-2774.

44 Marigold DS, Weeresteyn V, Patla AE, Duysens J. Keep looking ahead? Re-direction of visual fixation does not always occur during an unpredictable obstacle avoidance task. Experimental Brain Research 2007; 176: 32-42.

45 Graci V, Elliot DB, Buckley JG. Utility of peripheral visual cues in planning and controlling adaptive gait. Optometry and Visual Science 2010; 87: 21-27.

46 Rietdyk S, Rhea CK. The effect of visual characteristics of obstacles on risk of tripping and gait parameters during locomotion. Ophthalmic and Physiological Optics 2011; 31: 302-310.

47 Foulsham T, Walker E, Kingstone A. The where, what and when of gaze allocation in the lab and the natural environment. Vision Research 2011; 51: 1920-1931.

48 Hayashibe K. Apparent distance in actual, three-dimensional video-recorded, and virtual reality. Perceptual and Motor Skills 2002; 95: 573-582. 
49 Cicchetti DV. Guidelines, criteria, and rules of thumb for evaluating normed and standardized assessment instruments in psychology. Psychological Assessment 1994; 6: 284-290.

50 Holmqvist K, Nyström M, Andersson R, Dewhurst R, Jarodzka H, van de Weijer J. Eye Tracking: A Comprehensive Guide to Methods and Measures. Oxford: Oxford University Press, 2011.

51 Patla AE. Understanding the roles of vision in the control of human locomotion. Gait and Posture 1997; 5: 54-69.

52 Patla AE, Prentice SD, Robinson C, Neufeld J. Visual control of locomotion: Strategies for changing direction and for going over obstacles. Journal of Experimental Psychology 1991; 17: 603-634.

53 Patla AE, Vickers J. How far ahead do we look when required to step on specific locations in the travel path during locomotion?

Experimental Brain Research 2003; 148: 133-138.

54 Ayres TJ, Kelkar R. Sidewalk potential trip points: A method for characterizing walkways. International Journal of Industrial Ergonomics 2006; 36: 1031-1035.

55 Fotios S, Uttley J, Cheal C. Maintaining foveal fixation during a peripheral detection task. Lighting Research \& Technology 2015. DOI: 1477153515583710.

56 Commission Internationale de l'Eclairage. CIE 191:2010. Recommended System for Mesopic Photometry Based on Visual Performance. Vienna: CIE, 2010.

57 Fox J, Weisberg A. An R Companion to Applied Regression. Thousand Oaks, CA: Sage Publications, 2011.

58 Lighting Industry Association. Technical Statement LIA TS 24: SP Ratios and Mesopic Vision, 2013. Retrieved 24 June 2016, from http://www.thelia.org.uk/sites/default/files/ resources/LIA $\% 20 \mathrm{TS} 24 \% 20-\% 20 \mathrm{SP} \%$ 20Ratios\%20and\%20Mesopic\%20Vision.pdf
59 Fotios S, Unwin J, Farrall S. Road lighting and pedestrian reassurance after dark: A review. Lighting Research and Technology 2015; 47: 449-469.

60 Yang B, Fotios S. Lighting and recognition of emotion conveyed by facial expressions. Lighting Research and Technology 2015; 47: 964-975.

61 Cooper RA, Molinero AM, Souza A, Collins DM, Karmarkar A, Teodorski E, Sporner MS. Effects of cross slopes and varying surface characteristics on the mobility of manual wheelchair users. Assistive Technology 2012; 24: 102-109.

62 Pearlman J, Cooper R, Duvall J, Livingston R. Pedestrian pathway characteristics and their implications on wheelchair users. Assistive Technology 2013; 25: 230-239.

63 Agarwal A, Madan N, Chakrabarti N, Chakravarti D. Accessible and safe traffic environments for disabled school children: Proceedings of the 12th International Conference on Mobility and Transport for Elderly and Disabled Persons, Hong Kong, June 2-4: 2010.

64 Society of Automotive Engineers. UDC Uniform Detection Characteristics for Detecting Roadway Obstacles. SAE Technical Paper 2006-01-0948. Warrendale, PA: SAE International, 2006.

65 Lingard R, Rea M. Off-axis detection at mesopic light levels in a driving context. Journal of the Illuminating Engineering Society 2002; 31: 33-39.

66 Güler Ö, Onaygil S. The effect of luminance uniformity on visibility level in road lighting. Lighting Research and Technology 2003; 35: 199-213.

67 Rea MS, Ouellette MJ. Relative visual performance; a basis for application. Lighting Research and Technology 1991; 23: 135-144. 